\title{
Urinary Esch.coli isolates in tertiary care centre of south Kerala: Antibiogram and ESBL detection by phenotypic confirmatory disc diffusion testing
}

\author{
Riyaz Sheriff', Jesna Johnson², Prasobh KK. 3,*, Lakshmi Sarayu ${ }^{4}$ \\ ${ }^{\mathbf{1}}$ Assistant Professor, ${ }^{2}$ Trainee, ${ }^{\mathbf{3}}$ Associate Professor, ${ }^{4} \mathrm{HOD}$, Dept. of Microbiology, Azeezia Institute of Medical Sciences \& \\ Research, Kollam, Kerala, India
}

*Corresponding Author:

Email: microazeezia1@gmail.com

\begin{abstract}
Gram negative bacterial infections are the most important cause of Urinary Tract Infections (UTI) in India. Esch.coli being the most common isolate and has been resistant to commonly used antibiotics.

Materials and Methods: This study was done to assess the antibiotic sensitivity pattern of uropathogenic Esch.coli and to detect Extended-spectrum $\beta$ lactamase E coli isolated from samples collected in patients with urinary tract infections. Antibiotic sensitivity pattern was assessed using CLSI 2017 guidelines. ESBL detection was carried out using phenotypic Confirmatory Disc Diffusion Test

Results: 87 Esch.coli isolates were collected from urinary samples during the study period. Antibiotic sensitivity profiles showed that uropathogenic Esch.coli were sensitive to Amikacin, Gentamicin, Piperacillin-Tazobactum, Tetracyclines, Nitrofurantoin \& Carbapenams. Esch.coli exhibited resistance to cephalosprins and Fluroquinolones. 50 strains among the 87 isolates showed ESBL production by Phenotypic Confirmation Disc Diffusion Test (PCDDT)

Discussion: Esch.coli has established itself as a strong uropathogen. Esch.coli infections are more common in females due to anatomical factors. Most of the uncomplicated urinary tract infections happen in females of child bearing age group. There is an urgent need for the formulation of antibiotic policy for initiation of presumptive treatment. The way forward to handle antibiotic resistance is implementation of safe hands policy with handwashing, well informed usage of antibiotics for an appropriate duration along with implementation of universally accepted infection control protocols.
\end{abstract}

Keywords: Antibiotic policy Antibiotic resistance, PCDDT, Uropathogenic Esch.coli, Urinary Tract Infection.

\section{Introduction}

Gram negative bacterial infections are prevalent in India. The most common bacteria isolated in Urinary Tract Infections (UTI) are Esch.coli, Klebsiella and marginally Proteus. Other Enterobacteriaceae species form a small percentage of isolations. ${ }^{1}$ Esch.coli predominates other bacteria in uncomplicated UTI. The numbers are more so in female patients in child bearing age group. Over the last few decades, the antimicrobial resistance has been increasing mainly due to inappropriate use of antibiotics and over the counter pharmacy. ${ }^{5}$ The incidence of antibiotic resistance among gram negative infections in India is much more compared to western countries which have a higher prevalence of gram positive infections. Currently the government of India has suggested all healthcare institutions to develop their own antibiotic policy. Antibiotic policy development requires detailed information on the prevailing antibiotic resistance pattern in the geographical area of interest.

Many methods have been described for the detection of antibiotic sensitivity reporting. The most common methodology followed is from the Central Laboratory Standards Institute (CLSI) guidelines. ${ }^{3}$ The CLSI guidelines have standardized values for reporting response of the bacteria to antibiotics. The gold standard for determining resistance is undoubtedly the molecular level studies. In a resource poor country like India, this may not be possible in all centers dealing with bacterial isolates. Hence following simple detection techniques helps in getting an overall picture regarding the antibiotic resistance in the community. Insistence on PCR or molecular studies may result in loss of data from grass root level centers. This may hamper the development of an antibiotic policy which is representative of the local population. It is a well proven fact that the resistance pattern differs in every geographical area and hence the development of antibiotic policy based on data collected from local population gains importance. ${ }^{4}$

1980's saw the emergence of genes capable of affecting Beta lactams in Germany. The potential of these genes was clearly understood when nosocomial outbreak caused by Beta Lactamase strains in France in 1985. Beta Lactamase enzyme producing genes are carried on plasmids and can be easily shared among the gram negative bacilli. The enzymes produced as a result are capable of affecting same or different group of drugs. The genes have been evolving over time. They are classified and reclassified by Karen Bush \& George.A.Jacoby. ${ }^{6}$ Extended- Spectrum $\beta$ - lactamases (ESBLs) are enzymes that mediate resistance to extended spectrum cephalosporins, such as Cefotaxime, Ceftriaxone, Ceftazidime and the monobactum aztreonam. ${ }^{7}$ Such enzymes are most commonly found in Klebsiella pneumoniae and Escherichia coli, but they have also been detected in Klebsiella oxytoca, Proteus 
mirabilis, Salmonella species, and other members of the enterobacteriaceae and Pseudomonas aeruginosa.

Antibiotic resistance is a problem of deep scientific and therapeutic concern. Rapid detection in clinical laboratories is essential for the recognition of antimicrobial resistant organisms. Production of Extended spectrum $\beta$ - lactamases (ESBLs) is a significant resistance mechanism that impedes the antimicrobial treatment of infections caused by Enterobacteriaceae and is a serious threat to the currently available antibiotic armoury. Proper infection control practices and barriers are essential to prevent spread and outbreaks of ESBL producing bacteria. ${ }^{8}$

Detection of organisms producing these enzymes can be difficult, because the presence of ESBLs in a bacterial cell does not always produce a resistance phenotype when one is using the traditional MIC and disk diffusion interpretive criteria published by the Central Laboratory Standards Institute (CLSI). Strains producing AmpC $\beta$ - lactamases are also emerging in many areas. AmpC $\beta$ - lactamases are not inhibited by clavulanic acid or other beta lactamase inhibitors. Thus if any ESBL confirmatory test using clavulanic acid is not performed, many AmpC-producing strains may be presumed to be ESBL-producing strains.

The increased prevalence of enterobacteriaceae producing ESBLs creates a great need for laboratory testing methods that will accurately identify the presence of these enzymes in clinical isolates. Hence the study was undertaken to detect ESBL producers by using Central Laboratory Standards Institute screening test and Phenotypic Confirmatory Disc Diffusion Test (PCDDT) to compare their efficiency in detection. ${ }^{9}$

\section{Materials and Methods}

This prospective study was done at Azeezia Medical College Hospital during the period of January 2018 to June 2018 to assess the antibiotic sensitivity pattern of uropathogenic Esch.coli and to detect Extended-spectrum $\beta$ lactamase $\mathrm{E}$ coli isolated from samples collected in patients with urinary tract infections. Antibiotic Sensitivity pattern of ESBL isolates were assessed and analyzed. All non-repetitive midstream urine samples obtained during the study period were included in the study. A total of 1523 samples were received in the microbiology laboratory during the study period. This included 512 CCMSU (Clean Catch Midstream Urine Samples). After 24 hours of incubation at $37^{\circ} \mathrm{C} 260$ samples did not grow any bacterial colonies and were reported as No growths. 72 samples grew three or more type of bacterial colonies and were hence reported as mixed growths. Among the 180 samples which showed monobacterial significant growth of $>10^{5} \mathrm{cfu} / \mathrm{ml}$ of urine 21 belonged to gram positive organisms comprising of Staphylococcal sp, Enterococci \& Streptococci. 22 isolates were identified as Candida $s p$ and 8 isolates were identified as Pseudomonas aeruginosa. 129 isolates belonged to the family of Enterobacteriaceae comprising of Esch.coli, Klebsiella pneumonia, Enterobacter aerogenes, Proteus mirabilis \& Citrobacter sp. 87 isolates of Esch.coli were identified and included in the study.

\section{Processing of samples}

All samples were cultured on routine culture media by semi-quantitative method. Samples were inoculated on Mac Conkey and Blood Agar plate by streaking using sterile calibrated wire loop and incubated aerobically for $18-24 \mathrm{hrs}$ at $37^{\circ} \mathrm{C}$. Samples which showed monobacterial significant grown $\left(>10^{5}\right.$ $\mathrm{CFU} / \mathrm{ml}$ ) were included in this study. Isolation and identification was done based on their morphology in gram staining, cultural characteristics and biochemical reactions. $^{2}$

Antibiotic susceptibility testing of all isolates was performed by Kirby-Bauer's disc diffusion method and interpretation of the results was done as described in CLSI 2017. Antibiotic discs (Himedia Laboratories Pvt. Ltd. Mumbai) used were Ampicillin $(10 \mu \mathrm{g})$, Gentamicin $(10 \mu \mathrm{g})$, Ciprofloxacin $(5 \mu \mathrm{g})$, Levofloxacin $(5 \mu \mathrm{g})$, Cotrimonazole $(25 / 1.25 \mu \mathrm{g})$, Amoxicillinclavulanicacid $(20 / 10 \mu \mathrm{g}), \quad$ Piperacillin/Tazobactum $(100 / 10 \mu \mathrm{g})$, Norfloxacin $(10 \mu \mathrm{g})$, Amikacin $(30 \mu \mathrm{g})$, Ceftazidime $(30 \mu \mathrm{g})$, Ceftazidime+clavulanic acid $(20 / 10 \mu \mathrm{g})$, Cefuroxime $(30 \mu \mathrm{g})$, Cefotaxime $(30 \mu \mathrm{g})$, Imipenem $(10 \mu \mathrm{g})$, Aztreonam $(30 \mu \mathrm{g})$, Tetracycline $(30 \mu \mathrm{g})$, Nitrofurantoin $(300 \mu \mathrm{g})$, Tobramycin $(10 \mu \mathrm{g})$, Colistin $(10 \mu \mathrm{g})$, Etrapenem10 $\mu$ g), Doripenem $(10 \mu \mathrm{g})$, Meropenem $(10 \mu \mathrm{g})$. Bacterial suspension was made upto $0.5 \mathrm{Mc}$ Farland turbidity standards in peptone water.

\section{Procedure}

Antibiotic sensitivity testing was done using Kirby - Bauer method. Discs were applied using aseptic technique. Gap of $24 \mathrm{~mm}$ centre - centre was ensured as per CLSI guidelines. Plates were Incubated at $35 \pm 2^{\circ} \mathrm{C}$ and examined after a minimum of $16-18$ hours.

\section{Screening of ESBL producing Esch.coli}

According to CLSI guidelines, strains showing zone of inhibition of $\leq 22 \mathrm{~mm}$ for Ceftazidime and/or $\leq 17 \mathrm{~mm}$ for Cefpodoxime and/or $\leq 27 \mathrm{~mm}$ for Cefotaxime were considered for confirmation test for ESBL.ESBL producing Esch.coli isolates were the subcultured into sterile Nutrient Agar plates and incubated for 24-48 hours. The isolated single colonies were then used for further comparative studies. ESBL production among potential ESBL producing isolates was confirmed phenotypically using combined disc diffusion method. Comparison of the zone of inhibition was made for the Ceftazidime $(30 \mu \mathrm{g})$ vs. that of the Ceftazidime disc in combination with clavulanic acid $(30 / 10 \mu \mathrm{g})$, placed $25 \mathrm{~mm}$ apart (center to center). A difference in the inhibition zone diameter of $\geq 5 \mathrm{~mm}$ for 
a combination disc versus Ceftazidime disc alone confirmed ESBL production (Phenotypic Confirmatory Disc Diffusion Test).

\section{Results}

87 Esch.coli isolates were collected from urinary samples during the study period. Majority of samples were received from the General Medicine department, 14 isolates from patients attending out-patient department, 26 samples were from patients admitted in the Medicine ward and 9 samples from ICU patients grew monobacterial Esch.coli. Other departments which contributed to the samples were Gynecology, Urology, Pediatrics and General Surgery. 72 out of 87 samples were from female patients. The incidence of bacteruria increased from $2^{\text {nd }}$ decade of life and remained so till the $8^{\text {th }}$ decade.

Antibiotic sensitivity profiles showed that uropathogenic Esch.coli were sensitive to Amikacin (96.4\%), Gentamicin (71.4\%), Piperacillin-Tazobactum (91.8\%), Nitrofurantoin (92.9\%) \& Meropenam (100\%). Esch.coli exhibited resistance to cephalosprins and Fluroquinolones (Table1). 50 strains among the 87 isolates showed ESBL production by Phenotypic Confirmation Disc Diffusion Test (PCDDT). The antibiogram of ESBL Esch.coli showed considerable alteration in the sensitivity pattern. Except colistin sensitivity to all other class of antibiotics had reduced. Among various antibiotics tested Aminoglycosides and Nitrofurans showed lesser variation when tested with ESBL Esch.coli. Imipenam remained the better choice among carbapenams in ESBL isolates.

Table 1: Comparison of antibiotic sensitivity of uropathogenic Esch.coli isolates

\begin{tabular}{|c|c|c|c|}
\hline \multirow[b]{2}{*}{ Class } & \multirow[b]{2}{*}{ Antibiotics } & \multirow{2}{*}{$\begin{array}{c}\text { Esch.coli } \\
\mathrm{N}=87\end{array}$} & \multirow{2}{*}{$\begin{array}{c}\text { ESBL } \\
\text { Esch.coli } \\
\mathrm{N}=52\end{array}$} \\
\hline & & & \\
\hline Penicillin & Ampicillin & 23.5 & 0 \\
\hline \multirow{2}{*}{$\beta$ Lactam+Inhibitor } & Amox-clav & 19.8 & 0 \\
\hline & Pip-taz & 91.8 & 55.8 \\
\hline Cephalosporins II & Cefuroxime & 36.5 & 0 \\
\hline \multirow[t]{2}{*}{ III } & Cefotaxime & 35.6 & 0 \\
\hline & Ceftazidime & 41.9 & 0 \\
\hline Monobactum & Aztreonam & 42.9 & 0 \\
\hline \multirow[t]{4}{*}{ Carbapenams } & Imipenam & 87.2 & 73.1 \\
\hline & Doripenam & 80.3 & 13.5 \\
\hline & Etrapenam & 84.7 & 61.5 \\
\hline & Meropenam & 100 & 50 \\
\hline \multirow[t]{3}{*}{ Aminoglycosides } & Gentamicin & 71.4 & 59.6 \\
\hline & Tobramycin & 72.1 & 69.2 \\
\hline & Amikacin & 96.4 & 61.5 \\
\hline Tetracyclins & Tetracycline & 53.7 & 11.5 \\
\hline \multirow[t]{3}{*}{ Fluroquinolones } & Ciprofloxacin & 44.2 & 5.8 \\
\hline & Levofloxacin & 37.3 & 11.5 \\
\hline & Norfloxacin & 41.9 & 3.8 \\
\hline Folate Pathway (-) & Cotrimoxazole & 46.8 & 7.7 \\
\hline Nitrofurans & Nitrofurantoin & 92.9 & 82.7 \\
\hline Lipopeptides & Colistin & 100 & 100 \\
\hline Values mentioned at & n percentages & & \\
\hline
\end{tabular}

\section{Discussion}

Esch.coli belonging to the enterobacteriaceae family has it established itself as a strong uropathogen. Esch.coli infections are more common in females due to anatomical factors. Most of the uncomplicated urinary tract infections happen in females of child bearing age group. UTI is more common in females than in males as female urethra structurally found less effective for preventing the bacterial entry due to the proximity of the genital tract to urethra. The other main factors which make females more prone to UTI are pregnancy and sexual activity. In pregnancy, the physiological increase in plasma volume and decrease in urine concentration develop glycosuria in up to $70 \%$ women which ultimately leads to bacterial growth in urine. Also in the nonpregnant state the uterus is situated over the bladder whereas in the pregnant state the enlarged uterus causes pressure effect on the urinary tract. Sexual activity in females also increases the risk of urethra contamination as the bacteria could be pushed into the urethra during sexual intercourse as well as bacteria being massaged up the urethra into the bladder during child birth. ${ }^{12}$ In our study also, most of the samples were from female patients less than 50years 
of age. The treatment of uncomplicated urinary tract infections as per the national treatment guidelines -2016 is Nitrofurantoin or Cotrimoxazole or ciprofloxacin. But in clinical practice, the commonly used drugs are fluroquinolones and third generation cephalosporins. Most patients are treated empirically which results in antibiotic selection pressure. In our study, around 50\% of isolates exhibited resistance to cephalosporins. This huge number were also resistant to other group of drugs like fluroquinolones, macrolides, aminoglycosides. The antibiogram clearly shows that the patient with resistant Esch.coli infection will have to be on a longer course of injectable antibiotics. Some may even respond only to Carbapenems. ESBL changes the equation completely by bringing down the effectiveness of the commonly used antibiotics. The plasmid mediated transfer of antibiotic resistance has made the ESBL's resistant to Fluroquinolones. ${ }^{10}$ The net effect is the increase in the health expenditure. As per the estimates every person spends Rs.1713 on healthcare related expenditure per year. ${ }^{11}$ The resistant organisms are going to increase the expenditure drastically. There is an urgent need for the formulation of antibiotic policy keeping in mind the prevailing resistance pattern. As we are well aware that the antibiotic resistance exhibits a wide geographical variation, it is prudent for every healthcare facility to form its own statistics about resistance to antibiotics so that a strong antibiotic policy can be prepared on the basis of well authenticated resistance data. ${ }^{4}$ The way forward to handle antibiotic resistance is implementation of safe hands policy with handwashing, well informed usage of antibiotics for an appropriate duration along with implementation of universally accepted infection control protocols.

Funding: No funding sources.

Conflict of interest: None declared.

\section{References}

1. Koneman E.W, Allen S.D, Janda W M, Schreckenberger PC.. Colour Atlas of Diagnostic Microbiology $7^{\text {th }}$ edition San Francisco Lippin cott 2006 p 471 - 646

2. Gerald collee, Miles \& Watt. Tests for identification of Bacteria. Mackie \& McCartney Practical Medical Microbiology. $14^{\text {th }}$ edition. Pg 113-150
3. Performance Standards for Antimicrobial Susceptibility Testing. 27th edition. Clinical and Laboratory Standards Institute pg.62-73

4. Ghafur A1, Mathai D2, Muruganathan A3, Jayalal JA4, Kant R5, Chaudhary D and et al. Recommendations of "A roadmap- to tackle the challenge of antimicrobial resistance" - A joint meeting of medical societies of India. Indian J Cancer 2012;49(4):71-81.

5. Ganesh Kumar, Adithan, Harish, Sujatha, Gautam Roy \& Malini. Antimicrobial resistance in India: A review. $J$ Natural Sci Biol Med 2013;4(2):286-291

6. Karen Bush and George A. Jacoby. "Updated Functional Classification of $\beta$-Lactamases". Antimicrobial Agents and Chemotherapy 2010;54(3):969-76.

7. M. Gniadkowski."Evolution and epidemiology of extended-spectrum $\beta$-lactamases (ESBLs) and ESBLproducing microorganisms". Clin Microbiol Infect 2001;7:597-608.

8. Karadiya R, Hooja S, Pal N, et al. Prevalence and antimicrobial susceptibility of ESBL and AmpC $\beta$ lactamases producing Escherichia coli and Klebsiella pneumoniae from various clinical samples: an emerging threat. J Evolution Med Dent Sci 2016;5(32):1729-34.

9. L. Drieux, F. Brossier, W. Sougakoff and V. Jarlier."Phenotypic detection of extended-spectrum blactamase production in Enterobacteriaceae: review and bench guide. Clin Microbiol Infect 2008;14(Suppl. 1):90 103.

10. Robab Azargun1, Mohammad Reza Sadeghi, Mohammad Hossein, Soroush Barhaghi et al (2018)The prevalence of plasmid-mediated quinolone resistance and ESBLproduction in Enterobacteriaceae isolated from urinary tract infections. Infection and Drug Resistance 2018;11:1007-14.

11. Prinja S, Bahuguna P, Pinto AD, Sharma A, Bharaj G, et al., (2012) The Cost of Universal Health Care in India: A Model Based Estimate. PLoS ONE 7(1):e30362.

12. Maria Sindhura John, K. Meenakshi, P. Muni Lakshmi and P. Sreenivasulu Reddy. Prevalence and Distribution of Bacterial Pathogens Causing Urinary Tract Infections in Humans: A Study from Tertiary Care Hospital in AP, India. Int J Curr Microbiol App Sci 2015;4(2):251-57.

How to cite this article: Sheriff R., Johnson J., K. Prasobh, Sarayu L. Urinary Esch.coli isolates in tertiary care centre of south Kerala: Antibiogram and ESBL detection by phenotypic confirmatory disc diffusion testing. Int $J$ Med Microbiol Trop Dis 2018;4(4):222-25. 